\title{
The patient-dentist relationship and the future of dentistry
}

\author{
M. A. Bishop ${ }^{1}$
}

\section{Key points}

The patient-dentist relationship is a delicate partnership that forms the core of dentistry. The attack on this partnership by the General Dental Council has led to gross miscarriages of justice and the emergence of defensive dentistry. This essay considers the role of a governing body, the misconduct of the GDC and the response of the profession to the injustices perpetrated. The system of NHS general dental practice is considered in terms of quality and humanity and found to be failing in quality and lacking in humanity. The paper concludes that the General Dental Council must go and that NHS general dental practice needs to be terminated. The GDC is apparently not accountable to anyone but the practice of dentistry is accountable to the dentists. The profession will need to be courageous and take action to bring about radical change. A new governing body consisting of young dentists and older more experienced dentists will establish a proper system of professional standards and care for patients. A new, dentist-controlled private system of subsidised general dental practice will be introduced using government financial support for dentistry. The patient-dentist partnership will thus be able to move into a new era of quality and humanity.

\section{Where is dentistry in the UK going?}

Is dentistry heading for a black hole? Someone might say that dentistry is already in a black hole, a place from which there is no escape. Another one might add that it is in its current state because we put it there. We must therefore take responsibility and put it right. This essay discusses the problem of the gross misconduct of the General Dental Council (GDC) and its savage attack on dentists and its contempt for patients. It also discusses the unworkable and unacceptable nature of the NHS in general dental practice. Radical action to rectify the status quo is required on both fronts.

${ }^{1}$ Retired endodontist

Correspondence to: Mark Bishop

Email: pdrelfuture@gmail.com

Refereed Paper.

Accepted 10 October 2018

Published online 14 December 2018

DOI: 10.1038/sj.bdj.2018.1035

\section{Background}

As an endodontist working in my own private referral practice (2002-2015) I have watched with personal interest and general concern the development of various aspects of dentistry and especially the regulatory aspects. The advent, birth and rule of the Care Quality Commission (CQC) and the deterioration of the GDC have had a significant influence on my thoughts and behaviour. The influence and actions of governing bodies including the national government have had a devastating effect on the morale of dentists. The position of the dentist has been compromised to the detriment of the patient.

My own career has consisted of two parts, the first part was in research and teaching in the basic sciences (1974-2000) and the second, training in endodontics (MSc 2001) and clinical endodontics practice (1998-2017). The following essay is based on my experience as a practising dentist, my conversations with other dentists, my reading and my own consideration of what constitutes quality and justice in life.

\section{The patient-dentist relationship}

The oral cavity is a very sensitive area of the body and patients who need to see a dentist are often frightened. Oral and dental problems can cause pain and anxiety. The source of the pain is not always clear and diagnosis can be difficult. Even in a pain-free situation patient anxiety levels can be high and the technical demands on the dentist considerable. The dentist's skill in patient management, arriving at a diagnosis and performing treatment requires care and attention to detail. The process is often challenging and always takes time. The dentist-patient relationship is the core of dentistry; it is a delicate partnership in which trust and confidence are all-important ingredients. The practice of dentistry requires the support and encouragement of its governing body. Dentists who work on their own or who lead teams, have the right to assume that their governing body supports them. Younger dentists should be able to feel confident that their governing body really cares for them and their profession in much the 
same way as dentists care for their patients. In practice the GDC cares for neither the dentists it purports to support nor the patients it claims to protect. By damaging the patient-dentist relationship, the GDC attacks the core of dentistry. This is a disgraceful situation.

\section{The emergence of defensive dentistry}

Young and enthusiastic, hard-working dentists have been moved to write to the British Dental Journal about their plight. For example, Al Hassan $^{1}$ has networked with many young dentists who felt vulnerable, stressed and upset. The causes of these anxieties were almost never the dentistry but were financial issues and the GDC. On the GDC, Al Hassan ${ }^{1}$ describes 'colleagues being dragged through the coals over minor infractions which have nothing to do with public safety.' And dentists being 'subject to so much stress and mental degradation that their patient care will inevitably suffer. The whole profession begins to act much more defensively as a result, leading to worse outcomes for patients.' Not surprisingly, dentists don't want to work in general practice and seek more sheltered environments or go abroad. This is creating an unsustainable environment for dental care. As Al Hassan ${ }^{1}$ exclaims, 'We can't let this continue' and 'We are on the cusp of a mental health crisis.'

Martin Kelleher ${ }^{2}$ has also described the incompetence of GDC inquisitions which seize on minor bureaucratic errors, publicise the charges and thereby destroy the dentist's reputation before they are even tried over an issue that any well balanced human being can tell is unreasonable.

M G Hussain, ${ }^{3}$ a newly qualified dentist has noted that 'Defensive dentistry is real and being practised across the country [...]. Practising in this manner highlights the fear among the professionals [...].The fear is nothing more than the risk of being stripped naked by the GDC leaving you with a memory of a licence to practise dentistry.' Hussain $^{3}$ also asks, 'Why are we not educating the public and promoting a practitioner-patient relationship in which the public understands that the dentist is always working in your best interest and this principle is present from the beginning of their careers to retirement?' This is a very reasonable and sensible question put forward by a young dental graduate aspiring to excellence in the work place. This dentist feels the need to point out to the profession and the world that 'Dentists are humans carrying out highly skilled procedures within the confined beauty of the oral cavity and yes mistakes are made. To point the finger at the dentist and make him/her feel incompetent is wrong.'

A dentist friend of mine told me that fifty percent of dentistry is administration. This must be due to a feeling of the need to be accountable for one's every move, an outcome of defensive dentistry.

\section{The role of a governing body and the problems at the General Dental Council}

Warnings of the developing problems at the GDC were given in 2014 by Peter Ward ${ }^{4,5}$ in two articles, the second of which was entitled 'The entrepreneurs at the GDC. This drew an immediate response in the form of outrage at the GDC's unjustified enormous increase in dentists' annual registration fee. ${ }^{6}$ There was damning criticism of the GDC's authoritarian behaviour ${ }^{7}$ and the distorted composition of its membership. ${ }^{8}$ Concern over the deterioration of the GDC was also expressed by a former (in happier times) long-standing member of the council who described a recent gross miscarriage of justice perpetrated by the GDC. ${ }^{9}$

More recently John Renshaw ${ }^{10}$ has explained how the current problems at the GDC started in 2009 when constitutional changes were introduced. ${ }^{10}$ The changes led to the takeover of the council by lay persons. A previously rigorous system for dealing with complaints was replaced with two new assumptions 'that the patient was right and the dentist was wrong.' In his paper Renshaw $^{10}$ cites one example of an accused dentist who was investigated for four years only to find that her prosecutors had no case to answer! The terror and anguish that this dentist and others like her have been through as victims of the General Dental Council is unimaginable and it is an insult to civilised society.

The declared function of the General Dental Council is to protect patients and regulate the dental team. Surely the best way to do this would be to encourage dentists to do good work, to support them when the going gets tough and to nurture and to guide the younger members of the profession. Encouraging good dentistry must be the starting point in protecting patients or in preventing the need to protect patients. Is this not what it means to maintain professional standards? If despite doing these things there are major grievances among patients and instances of misconduct among the dentists then the governing body must step in and perform its more judicial role in protecting patients. In recent times the GDC has abused its role in protecting patients by seizing on a trivial complaint as an excuse for a witch hunt on the dentist, suspension and sometimes exclusion from the dental register. Does the GDC have any sense of judgement? It behaves as though it does not understand the meaning of justice and its behaviour is too often malicious. From a moral point of view it appears to have no compass, the GDC does not know where it is going. What, one might reasonably ask is the actual current goal of the GDC, the destruction or annihilation of the dental profession? If so, why? Is there an ulterior government led motive? Is the downgrading of the profession of dentistry as we know it in the pipeline?

The GDC is responsible for determining standards in the education and training of dentists, including continuing professional development (CPD). Using an example of their current work in the name of CPD, Hancocks ${ }^{11}$ has warned us that their recent enhanced CPD plan (eCPD) would be better named as 'excessively confusing (ecCPD) [...] and is set to trouble GDC registrants for years to come.' In the words of Hancocks, ${ }^{11}$ 'It is another meaningless imposition piled high with others that crush, stifle and cause increasing levels of burnout.' Is the General Dental Council a rogue organisation?

In 2014, Stephen Hancocks ${ }^{12}$ asked what would happen if the GDC 'ceased to exist, to what extent would dentistry in this country collapse?' It is pertinent now to ask what justification the GDC has for its existence. It refuses to engage in meaningful negotiation with the profession, ${ }^{13}$ it willfully destroys the careers of innocent professionals, it misleads the patients it claims to protect, it overcharges the dentists for their right to practise, it does not understand the meaning or value of continuing education and its accountability is in question. This rogue organisation also purports to set standards for the education and training of dentists and other dental care professionals.

How has this situation come about? Is it because of a maniacal leader in the chair of the $\mathrm{GDC}^{14}$ or is the national government also involved? Martin Kelleher ${ }^{2}$ certainly believes that the state is involved. Kelleher ${ }^{2}$ has suggested a long list of issues that the government and the GDC will need to address (should they be given the opportunity) in order to gain the trust of a profession they have long been terrorising. 


\section{How well has the dental profession responded to the misconduct of the General Dental Council?}

How well has the dental profession responded to the injustices so far? The status quo is an atrocious one so the answer is that we have not responded adequately. According to Westgarth, ${ }^{15}$ the profession goes through the motions only and he asks, 'Have we become so entrenched in the problems that we can no longer see solutions?' If so, we are in a black hole; there is no escape from a real black hole but we must get out of the metaphorical one we have created.

Examples of action taken so far include a demonstration by dentists following a 'no confidence' in the GDC motion at a conference in London which took place in 2014. There was a call from the British Dental Association ${ }^{16}$ in 2016 for the chairman of the GDC, Dr Bill Moyes, to resign following a damning report on the council published by the Professional Standards Authority. The call for the resignation of the chair included a long list of the chairman's and the council's failings, incompetence, ignorance and deviousness.

John Renshaw ${ }^{10}$ who has 50 years' experience of active involvement in dental politics and who understands the responsibilities of the GDC has stated respectfully that, 'Enough is enough' and 'We need and deserve our own profession's case to be listened to.'

These actions and sometimes polite writings have served to demonstrate and publicise the fact that there is a serious problem, but if we are proposing to solve the problem, it is clear that a more radical approach is needed. As Peter Ward ${ }^{17}$ has pointed out this is a matter of human rights and from a legal and constitutional point of view the GDC is accountable to no one! Yet the practice of dentistry is accountable to the dentists, is it not? The dentists know and care about dentistry, do we not? The dentists should be governing their profession. Why are we not?

\section{The National Health Service in general dental practice}

A young applicant to dental school was moved to write to the British Dental Journal in 2011 about his work experience in both NHS and private dental practice. R. Harlow ${ }^{18}$ could see that the time available for proper communication between patient and dentist created bad attitudes among the patients. On the other hand, 'In private practice, where the time restrictions are independently set, the dentist patient relationship seems to be far better. ${ }^{18}$ As a qualified dentist I am baffled and bemused as to how general practice functions in the National Health Service. The National Health Service ignores patients' well-being and provides a distorted and cynical attitude to the costing of dental treatment. A consequence of this is that NHS dentists sometimes see 40 or 50 patients in a single day! Dentistry takes time and the patient-dentist relationship is all important (see above). Any clear thinking person knows in his or her heart that this is the case - it's obvious. It seems that the constrictions and restrictions of the NHS and the compliance of the dental profession have colluded to produce the present sorry state of affairs.

An experienced Italian dentist had the opportunity to witness NHS dentistry in action and he wrote to the BDJ in 2016 about his observations and conclusions. M. Rossi ${ }^{19}$ was 'horrified to witness the UDA system imposed on dentists in the UK.' He gave a simple general description of some dental and periodontal procedures and his estimate of the time needed to perform them and compared this with NHS expectations. The NHS expected about 3.4 times as much work to be done in the time that Rossi ${ }^{19}$ deemed reasonable. Rossi ${ }^{19}$ went on to comment on the GDC as 'the most demanding and pedantic regulator [... possibly in the world.' Rossi ${ }^{19}$ questioned the sanity of any dentist who would agree to work under such conditions.

Martin Kelleher ${ }^{2}$ has discussed in detail the relationship between funding, time availability and quality of work. It is not possible to achieve quick, high quality work at a low price. Kelleher ${ }^{2}$ asks, 'Is it time to stop lying to people that "cheap, quick and highest quality is possible....?"

In a recent article Hancocks ${ }^{20}$ acknowledged both the seventieth birthday of the NHS and the lack of any proclamation to bring an honest end to NHS dentistry. Hancocks also noted that there was no political will to advance dental care. This is a statement of failure and an admission of regression. The unworkable and demoralising system of NHS general practice dentistry must be brought to a close; it is begging for action from the profession.

\section{The status of the General Dental Council}

The status of the General Dental Council as the governing body which maintains professional standards in dentistry and which protects patients is no longer tenable. The evidence I have provided in this essay speaks for itself: the GDC is the enemy of the dental patient and the enemy of the dental profession. The General Dental Council needs to go.

\section{The future of dentistry after the General Dental Council has gone}

Once the General Dental Council has gone a new organisation of enlightened persons brimming with vitality and enthusiasm will emerge. This new body, which will include younger members, will help to lead the profession towards a future filled with quality and humanity.

At the present time both the government and the GDC are destructive influences; neither body knows or cares about dentistry. The GDC is not accountable to anyone. ${ }^{17}$ The dentists know and care about dentistry. The dentists are responsible and accountable for the dentistry they do. The dentists must therefore correct the situation and make it right, fair and proper. We need a new system of regulation that respects both the patients and their dentists.

Senior experienced dentists as well as a good number of younger personnel will establish a new way forward. In the words of a former president of the GDC (1999-2003), Nairn Wilson, ${ }^{21}$ the new body will need 'to promote modern, "right touch" regulation of the profession.' In order to regain the confidence and support of the profession and to protect the public 'a complete overhaul of the regulation of the profession' may be needed. It will need 'the right people to apply it the right way, at the right time and with the right force to achieve the right result.' ${ }^{21}$

Once the new governing body has been installed it will get to work and establish a new system of justice and fair play for patients and dentists. Negotiations for the termination of NHS general dental practice and its transfer into private care will be instigated. A method of transition will be formulated whereby existing levels of government financial support for dentistry will be maintained in order to facilitate the process. The new practices will establish their own methods and fee structures. The fee structures will be subsidised by the government but controlled by the dentists. It will be hard work and it will take time but the reward will be a new workplace and satisfaction for patients and dentists alike.

A sense of urgency is required. A change of direction away from the black hole, from the current state of nonsense to a state of common sense is needed. For each day that goes by under the present regime the injustice will continue. A dentist can apparently survive 
today with hands tied and will thwarted but this is degrading for both the patient and the dentist. Is it not our duty to create an environment of true quality and true humanity where patients and dentists are both winners?

I call upon the twelve members of the General Dental Council to resign immediately.

\section{Acknowledgement}

I should like to thank Martin Kelleher for encourag ing me to write this essay.

1. Al Hassan A. Defensive dentistry and the young dentist - this isn't what we signed up for. Br Dent J 2017; 223: 757-758.
2. Kelleher M. State-sponsored dental terrorism? Br Dent $J$ 2017; 223: 759-764.

3. Hussain M G. A dental student's journey to joining a profession which is failing the very people it cares for. $\mathrm{Br}$ Dent J In Pract 2018; 31: 20-21.

4. Ward P. Human beans. Br Dent J 2014; 216: 543.

5. Ward P. The entrepreneurs at the GDC. Br Dent J 2014; 217: 549.

6. Sellers J J. ARF Hike - You cannot be serious. Br Dent J 2015; 218: 212

7. Marks C. Get off our backs. Br Dent J 2015; 218: 212

8. Pairman J S. The dental police force. Br Dent J 2015; 218: 212.

9. Bell M. Gross miscarriage of justice. Br Dent J 2015; 218: 92.

10. Renshaw J. Serious concerns about the General Dental Council's performance and direction of travel. Br Dent $J$ 2018; 224: 213-214.
11. Hancocks S. yCPD. Br Dent J 2018; 224: 195.

12. Hancocks S. What if? Br Dent J 2017; 217: 257

13. Hancocks S. Again and again and will it be again? $\mathrm{Br}$ Dent J 2017; 223: 797.

14. Ward P. Whistling in the dark. Br Dent J 2016: 220: 1 .

15. Westgarth D. Going through the motions. Br Dent J In Pract 2018; $31: 7$.

16. BDJ News. GDC chair must go says British Dental Association. Br Dent J 2016; 220: 47.

17. Armstrong, M, Ward P. The GDC - a law unto itself? $\mathrm{Br}$ Dent J 2017: 223: 815-818.

18. Harlow R. Just another number? Br Dent J 2011; 211: 306.

19. Rossi M. NHS dentistry - UDA disaster. Br Dent J 2016: 221: 279.

20. Hancocks S. The Birthday party. Br Dent J 2018; 225: 1.

21. Wilson N. Presidential address. Br Dent J 2015; 218: 503-504. 